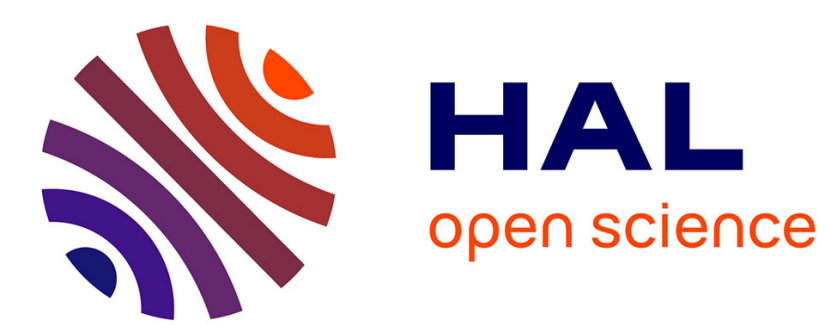

\title{
The tumultuous childhood of the Solar System
}

Yves Marrocchi, Laurette Piani

\section{To cite this version:}

Yves Marrocchi, Laurette Piani. The tumultuous childhood of the Solar System. Nature Astronomy, 2019, 3 (10), pp.889-890. 10.1038/s41550-019-0868-y . hal-02357491

\section{HAL Id: hal-02357491 \\ https://hal.univ-lorraine.fr/hal-02357491}

Submitted on 10 Nov 2019

HAL is a multi-disciplinary open access archive for the deposit and dissemination of scientific research documents, whether they are published or not. The documents may come from teaching and research institutions in France or abroad, or from public or private research centers.
L'archive ouverte pluridisciplinaire HAL, est destinée au dépôt et à la diffusion de documents scientifiques de niveau recherche, publiés ou non, émanant des établissements d'enseignement et de recherche français ou étrangers, des laboratoires publics ou privés. 


\title{
METEORITES The tumultuous childhood of the Solar System
}

\author{
Yves Marrocchi and Laurette Piani
}

The peculiar carbon isotopic compositions of carbonates in the Tagish Lake meteorite suggest that D-type asteroids accreted in the outer part of the protoplanetary disk-beyond $10 \mathrm{AU}-$ before being dispersed sunwards to the main asteroid belt.

Asteroids are airless bodies of varying sizes revolving around the Sun and are considered to be the remnants of planetary formation processes. Although asteroids have been visited by several past and current space missions, asteroid formation condition, timing and location remain poorly understood. Writing in Nature Astronomy, W. Fujiya and colleagues ${ }^{1}$ use the carbon isotope compositions of a unique meteorite -the Tagish Lake chondrite- to get hints on the formation location of D-type asteroids, kindred to this meteorite.

From the discovery of the first asteroids in the early nineteenth century, the asteroid belt, located between Mars and Jupiter (Fig. 1), was long considered to be a 'living relic' of planetary formation, with asteroids remaining at the heliocentric distance at which they formed. Opinions started to change some 40 years ago with the discovery of compositional variations as a function of distance from the $\operatorname{Sun}^{2}$. Since then, the census of the orbital and compositional characteristics of tens of thousands of asteroids ${ }^{3}$ revealed the structure of the asteroid belt to be even more complex, with asteroids showing a large range of eccentricities and inclinations, as well as the radial mixing of different asteroid types across the asteroid belt.

We know now that the peculiar properties of the main asteroid belt are the direct consequences of the tumultuous childhood and chaotic history of the Solar System. Numerical simulations show that the migration of giant planets over distances of several astronomical units (AU) shaped the Solar System during its first billion years of evolution ${ }^{4}$. The asteroid belt thus resulted from large-scale gravitational perturbations induced by planetary migration events 4.56 and $4.1 \mathrm{Ga}$.

Among the wide diversity of asteroids in the main belt, D-type asteroids are rare, potentially organic-rich rocky bodies with compositions that have likely remained unchanged since their formation; they are located in the outer asteroid belt and constitute the majority of the Jupiter Trojans. Numerical simulations suggest that D-type asteroids formed beyond $\sim 15$ AU from the $\operatorname{Sun}^{5}$ and potentially as far as the Kuiper Belt (30-50 AU) ${ }^{6}$, but their origin, dynamical evolution, and mineralogical characteristics remain largely unknown. No confirmed D-type meteoritic sample is known, with the possible exception of the Tagish Lake chondrite that was recovered after its fall in 2000. This carbon-rich meteorite is characterized by unique features, including large $\mathrm{D}$ and ${ }^{15} \mathrm{~N}$ enrichments and high concentrations of presolar grains and carbonate minerals 7,8 .

Fujiya et al. ${ }^{1}$ take advantage of the high abundance of carbonates in the Tagish Lake chondrite to estimate where D-type asteroids accreted within the protoplanetary disk. The idea is quite simple. The precipitation of chondritic carbonates required a carbon source whose origin can be tracked based on the carbon isotopic compositions of the carbonates. Within chondritic parent bodies, three $\mathrm{C}$ sources are generally invoked ${ }^{9}$ : (i) inorganic cometary carbonaceous ices $\left(\mathrm{CO}, \mathrm{CO}_{2}\right)$, (ii) presolar grains, and (iii) soluble organic matter. Until now, soluble organic matter was considered as the best candidate to explain the range of carbon 
isotopic compositions observed in carbonates of hydrated CM chondrites ${ }^{9}$. However, Fujiya and co-authors ${ }^{1}$ show that the amount of soluble organic matter in Tagish Lake is too low to have produced its high abundance of carbonates. More critically, the unusual ${ }^{13} \mathrm{C}$-rich carbon isotopic composition of Tagish Lake carbonates reported by Fujiya et al. ${ }^{1}$ cannot be explained without invoking the accretion of large amounts of $\mathrm{CO}_{2}$ cometary ices.

Based on these results, Fujiya and co-authors ${ }^{1}$ calculate that the $\mathrm{CO}_{2} / \mathrm{H}_{2} \mathrm{O}$ ratio of ice accreted by the Tagish Lake parent body is similar to that estimated for cometary ice. The carbon budget of the Tagish Lake parent body was thus dominated by cometary ice, which is at odds with the carbon sources considered for other carbonaceous chondrites. Fujiya et al. ${ }^{1}$ conclude that the Tagish Lake parent body formed beyond $10 \mathrm{AU}$, in regions of the protoplanetary disk that were cold enough for $\mathrm{CO}_{2}$ to condense (Fig. 1). This supports an outer Solar System origin for D-type asteroids and suggests that the violent dynamical evolution of the giant planet orbits led to large-scale perturbations in the Solar System upon the transport of primitive trans-Neptunian objects to the asteroid belt.

Despite its peculiar features, the Tagish Lake chondrite is surprisingly not so structurally different from other carbonaceous chondrites that are thought to have formed closer to the Sun. All the ingredients of the chondrite recipe are present: calcium-aluminiumrich inclusions (CAIs), chondrules, and fine-grained matrix. If the Tagish Lake parent body indeed accreted in the outer Solar System as claimed by Fujiya and co-authors ${ }^{1}$, it would have deep implications for the dynamics of the protoplanetary disk. It would mean that large-scale outward mixing must have occurred during the disk's evolution, as previously inferred from the presence of CAI- and chondrule-like objects in the Stardust cometary samples ${ }^{11}$, because it is unlikely that reduced high-temperature assemblages (CAIs and chondrules) formed in the cold, water-rich outer zones of the protoplanetary disk. Furthermore, the fact that Tagish Lake chondrules have oxygen isotopic compositions similar to those of CM carbonaceous chondrites, which are thought to be representative of the most common C-type asteroids ${ }^{11}$, could be taken as an argument that chondrules formed from a homogeneous oxygen isotopic reservoir in the inner protoplanetary disk before being dispersed throughout the disk. Fujiya et al. ${ }^{1}$ do not discuss these issues in detail nor do they address the possible similarity of the oxygen isotopic compositions of CI, CM, and Tagish Lake alteration fluids ${ }^{10,13-15}$. Indeed, no significant heavy isotope enrichment seems to be present in Tagish Lake water and carbonates $^{14-15}$, although such enrichments are expected for objects that formed in the outer Solar System where interstellar water ice grains would have dominated the water budget ${ }^{16}$. Interpreted in the framework of the protoplanetary disk's dynamical evolution, this could imply that the oxygen isotopic composition of water is also homogeneous at a large-scale.

The results reported by Fujiya et al. ${ }^{1}$ therefore raise many questions about the origin of isotopic variations, such as the role of photochemical processes in producing ${ }^{13} \mathrm{C}$ enrichments $^{17}$, and the general structure of the protoplanetary disk. Future comparison of the present data with samples of hydrated B- and C-type asteroids expected to be returned to Earth by the OSIRIS-REx and Hayabusa 2 missions will thus be fundamental to further quantifying large-scale pertubations in the early Solar Sytem.

\section{Yves Marrocchi and Laurette Piani}

Centre de Recherches Pétrographiques et Géochimiques (CRPG), CNRS, UMR 7358, Université de Lorraine, 15 rue Notre Dame des Pauvres, 54500 Vandoeuvre-lès-Nancy, France.

e-mail: Yves Marrocchi (yvesm@crpg.cnrs-nancy.fr) and Laurette Piani (piani@crpg.cnrsnancy.fr) 


\section{References}

${ }^{1}$ Fujiya, W. et al. Nat. Astron. this issue

${ }^{2}$ Gradie, J. \& Tedesco, E. Science 216, 1405-1407 (1982)

${ }^{3}$ DeMeo, F.E. \& Carry, B. Nature 505, 629-635 (2014)

${ }^{4}$ Walsh, K. J. et al. Nature 475, 206-209 (2011)

${ }^{5}$ Levison, H.F. et al. Nature 460, 364-366 (2009)

${ }^{6}$ Vokrouhlický, D. et al.. Astron. J. 152, 39 (2016)

${ }^{7}$ Hiroi, T. et al. Science 293, 2234-2236 (2001)

${ }^{8}$ Nakamura-Messenger, K. et al. Science 314, 1439-1442 (2006)

${ }^{9}$ Fujiya, W. et al. Geoch. Cosmoch. Acta 161, 101-117 (2015)

${ }^{10}$ Vacher, L. et al. Geoch. Cosmoch. Acta 217, 271-290 (2017)

${ }^{11}$ Zolensky, M.E. et al. Science 314, 1735-1739 (2006)

${ }^{12}$ Russell, S. et al. Geoch. Cosmoch. Acta 74, 2489-2499 (2010)

${ }^{13}$ Clayton, R.N. \& Mayeda, T.S. Geoch. Cosmoch. Acta 63, 2089-2104 (1999)

${ }^{14}$ Leshin, L.A. et al. LPSC XXXII 1843 (2001)

${ }^{15}$ Baker, L. et al. Meteorit. Planet. Sci. 37, 977-985 (2002)

${ }^{16}$ Lyons, J.R. \& Young, E.D. Nature 435, 317-320 (2005)

${ }^{17}$ Lyons, J. R. et al. Nat. Commun. 9, 908 (2018)

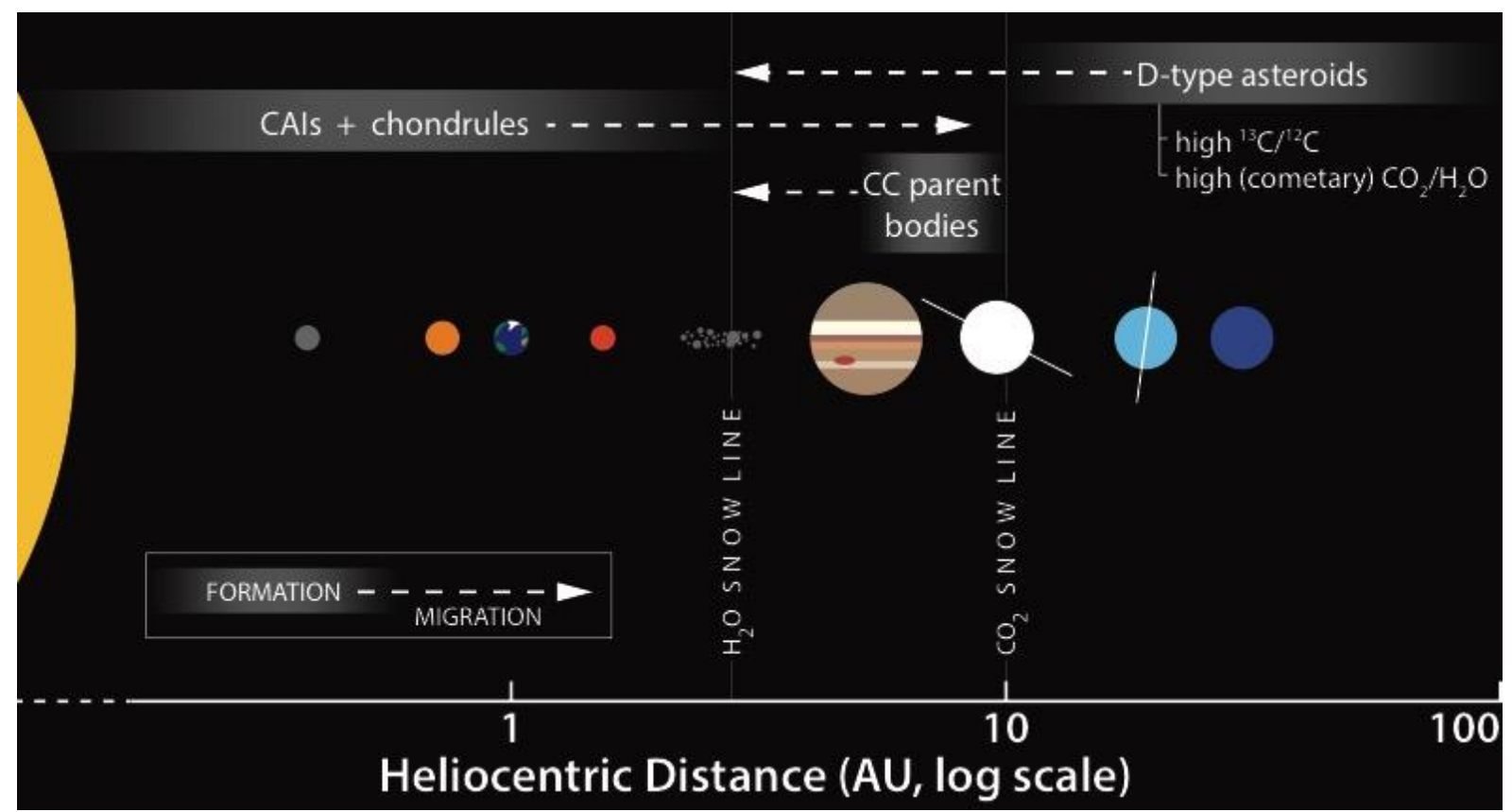

Fig. 1: Schematic representation of the Solar System showing the location of the different planets and the asteroid belt. The data reported by Fujiya et al. suggest that D-type asteroids were formed in the outer part of the Solar System before being implanted in the main asteroid belt. $\mathrm{CC}=$ carbonaceous chondrites, $\mathrm{CAIs}=$ calcium-aluminum-rich inclusions 